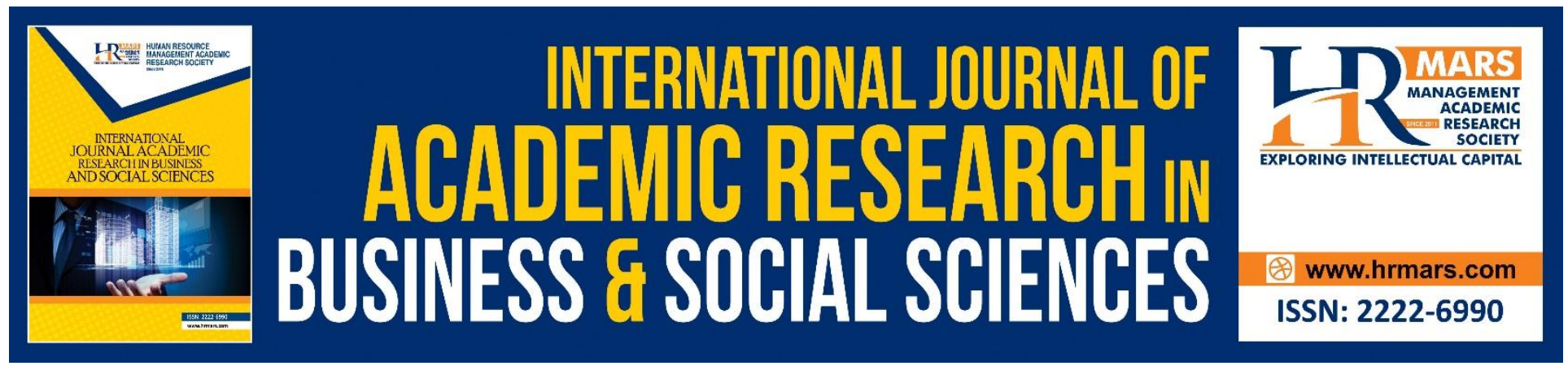

\title{
Factors Influencing the Intention to Use Affiliate Marketing: A Conceptual Analysis
}

\section{Zurina Patrick, Ong Choon Hee}

To Link this Article: http://dx.doi.org/10.6007/IJARBSS/v9-i2/5608

DOI: $\quad 10.6007 /$ IJARBSS/v9-i2/5608

Received: 17 Jan 2019, Revised: 27 Feb 2019, Accepted: 02 March 2019

Published Online: 14 March 2019

In-Text Citation: (Patrick \& Hee, 2019)

To Cite this Article: Patrick, Z., \& Hee, O. C. (2019). Factors Influencing the Intention to Use Affiliate Marketing: A Conceptual Analysis. International Journal of Academic Research in Business and Social Sciences, 9(2), 701710.

Copyright: (C) 2019 The Author(s)

Published by Human Resource Management Academic Research Society (www.hrmars.com)

This article is published under the Creative Commons Attribution (CC BY 4.0) license. Anyone may reproduce, distribute, translate and create derivative works of this article (for both commercial and non-commercial purposes), subject to full attribution to the original publication and authors. The full terms of this license may be seen

at: http://creativecommons.org/licences/by/4.0/legalcode

Vol. 9, No. 2, 2019, Pg. 701 - 710

http://hrmars.com/index.php/pages/detail/IJARBSS

JOURNAL HOMEPAGE

Full Terms \& Conditions of access and use can be found at http://hrmars.com/index.php/pages/detail/publication-ethics 


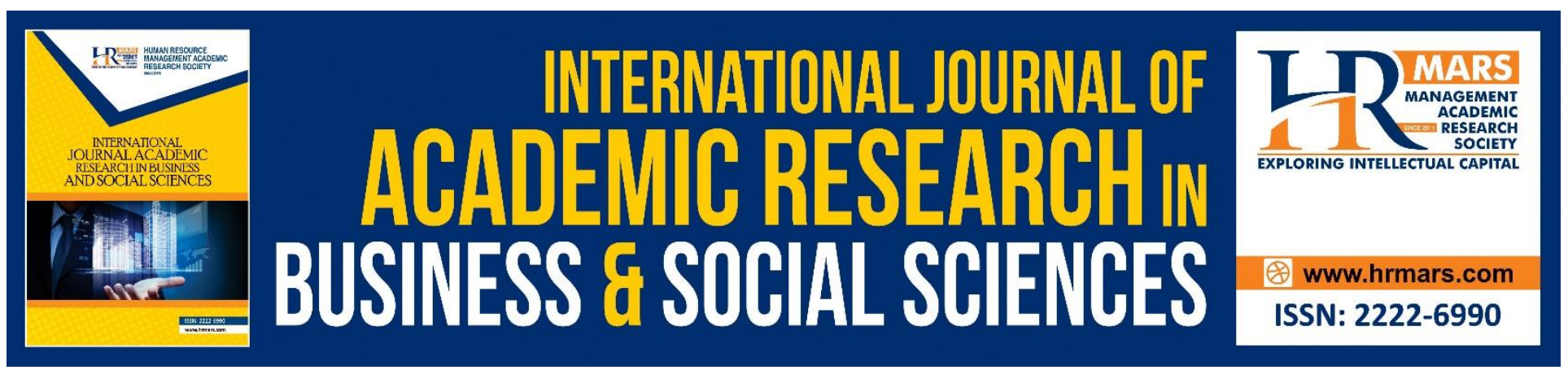

\title{
Factors Influencing the Intention to Use Affiliate Marketing: A Conceptual Analysis
}

\author{
Zurina Patrick, Ong Choon Hee \\ Azman Hashim International Business School, Universiti Teknologi Malaysia, Johor, Malaysia. \\ Corresponding Author: zurinapatrick@gmail.com
}

\begin{abstract}
Internet and technology advances enable all business organizations to engage in the e-commerce market. The use of multichannel strategies is costly. Affiliate marketing has emerged as one of the wildest growing online marketing and e-commerce strategies to increase sales. Perfections in online activities via affiliate marketing have a significant effect on the organization's product visibility, advertising cost, and return on investment (ROI). These are critical components that an organization need to secure in order to gain the ability to create brand positions in the e-commerce market. Understanding the factors that contribute to the engagement of affiliate marketing in an organization is crucial because it helps to identify success factors that influence the intention to use affiliate marketing. From this understanding, refreshing changes or alternatives to current online marketing practices, organization strategies, and advertising techniques can be easily transformed to reduce the advertising costs. This study only focused on three dominant factors which influence the behavioral intention to use specific technology (i.e. affiliate marketing) which are relative advantage, compatibility, and observability. Relative advantage is defined as the level at which the current practice is perceived to be lower than innovation and is associated with a diversity of facilities, satisfaction, social, and economic diversity. Compatibility refers to the level at which the innovation is perceived consistent with previous ideas, socio-cultural values or perceived innovation is necessary. On the other hand, observability is the stage where other users or other parties, but not the business owner can see the positive results of using the technology. Thus, through the understanding of these factors, the researcher aims to show a better understanding of the affiliate marketing concept and the factors that influence the intention to use affiliate marketing.
\end{abstract}

Keywords: Intention to Use Affiliate Marketing, Relative Advantage, Compatibility, Observability.

\section{Introduction}

Internet and technology advances enable all businesses to engage in the e-commerce market. Technology not only gives new choices and meets every customer's needs; business organizations can also gain significant benefits as digital technology enables them to engage in innovative and 
productive strategies. As noted by Yap and Chua (2018), digital technology constantly thought to be the best driver of change, especially in meeting the needs of today's society. In addition, the growth of online buyers reflects the economic changes and social development of the country (Wong, Wong, and $\mathrm{Ke}, 2018)$. Most organizations start paying close attention to the importance of creating a strong "digital relationship" with customers (Phillips, 2015) through various online marketing options that can be incorporated into the organization's marketing activities or strategy in a different way to suit their needs. However, the use of multichannel strategies is costly. Affiliate marketing has emerged as one of the wildest growing online marketing and e-commerce strategies to increase sales (Fox and Wareham., 2010). It seems to have better potential than previous online marketing activities (Duffy, 2005; Janssen and van Heck, 2007). There is a growing interest in affiliate marketing in organizations as many organizations are striving to position itself in the e-commerce market through affiliates assistance (Mariussen, Daniele, and Bowie, 2010; Newton and Ojo, 2018). Perfections in online activities via affiliate marketing have a significant effect on the organization's product visibility, advertising cost, and return on investment (ROI). These are critical components that an organization need to secure in order to gain the ability to create brand positions in the e-commerce market (Lammenett, 2017). Affiliate marketing is also directly linked to a healthy performance, new customer acquisition, and higher productivity which are closely related to an organization's cost efficiency for advertising (Brear and Barnes, 2008). Affiliate marketing was a relatively current study which specified that this technique has so many advantages over previous online marketing practices, where it reinforces the function of internet promotional activities. The study of affiliate marketing confirmed that this tool has become a standard tool for organizations with internet business activities (Beranek, 2018). In this situation, organizations with internet business activities or involve in ecommerce market-should consider using affiliate marketing to increase sales (Fox and Wareham., 2010). Understanding the factors that contribute to the engagement of affiliate marketing in an organization is crucial because it helps to identify success factors that influence the intention to use affiliate marketing. From this understanding, refreshing changes or alternatives to current online marketing practices, organization strategies, and advertising techniques can be easily transformed to reduce the advertising costs. There are several factors that might influence the intention to use affiliate marketing such as perceived usefulness, relative advantage, compatibility, observability, social influence, and many more. Nevertheless, this study only focused on three dominant factors which influence the behavioral intention to use specific technology (i.e. affiliate marketing). The three factors discussed in this study were relative advantage, compatibility, and observability. This study aims to form a conceptual framework which contributes towards the intention to use affiliate marketing.

\section{Intention to Use Affiliate Marketing}

Affiliate marketing means organization hired trusted affiliate marketers (third-party publishers) to promote the goods and services of an organization through its website (Duffy, 2005; Lammenett, 2017; Mazurek and Kucia, 2011). Thus, affiliate marketing can also be defined as a technique for an organization to outsource the selling of its products. This technique naturally use advertising channels, such as product data file, text links or banners, and for every customer clicks on the link (click), customer contacts the organization (leads), or customer makes a purchase (sale) of the 
recommended products, the affiliate marketer receives a commission from the organization (Fox and Wareham., 2010). On the other hand, Dwivedi, Rana, and Alryalat (2017) claimed that affiliate marketing is a type of performance-based Internet marketing and this performance-based internet marketing normally reflect the amounts of revenue (organization) and commissions earned (affiliate marketer). In a simple word, the success of affiliate marketing can be seen through the increases in an organization's sales. It usually involves three parties, namely organizations, affiliate marketers, and customers (Mazurek and Kucia, 2011). A previous theory developed by (Rogers, 1983) namely diffusion of innovation (DOI) explained how, why, and at what stage of the new ideas and technologies spread. Diffusion is the process in which innovation is communicated through certain channels (a special type of effective communications) over time among members of the social system (Rogers, 1983). This theory refers to the process that occurs when individuals or organizations begin to adopt practices, philosophies, ideas, new technologies, and so forth (Kaminski., 2011). Rogers (1983) identified five determinants in the DOI model, namely observability, compatibility, relative advantage, complexity, and trialability. At the organizational level, Rogers defined relative advantage as the extent to which the new technology is viewed better than current practice by ease, satisfaction, social prestige and economically measured, compatibility as the extent to which the new technology is compatible with the current value, experience, and there is a demand that encourages the adoption, observability as the extent to which the results of adopting the new technology is noticeable by others, complexity as the extent to which new technology is considered to be difficult to understand and use by potential adopter, and trialability as the extent to which the potential adopter has the ability to test the new technology based on short-term agreements. Research by Lou, Tian, and Koh (2017), found out that relative advantage, observability, and compatibility are the most prevailing factors that lead to technology adoption while complexity and trialability did not have an effect on technology acceptance or usage. This finding is consistent with many other innovative studies by Jansson (2011) and Sun, Cegielski, Jia, and Hall (2018). In this study, the intention to use affiliate marketing has been proposed as the dependent variable in the theoretical framework (refer to figure 1). The influence of relative advantage, compatibility, and observability to the intention to use affiliate marketing would be debated in the following sections of this paper.

\section{Relative Advantage}

Relative advantage is defined as the level at which the current practice is seen to be lower than innovation (Rogers, 2003) and is associated with a diversity of facilities, satisfaction, social, and economic diversity. Relative advantages have been widely studied in areas such as e-commerce (Shaltoni, West, Alnawas, and Shatnawi, 2018). Affiliate marketing has a relative advantage over previous online marketing practices, where it reinforces the function of internet promotional activities. Many researchers have suggested that the relative advantage of new technology adoption is one of the predictors most frequently used in technology adoption research (Puklavec, Oliveira, and Popovič, 2018). An innovative study by Zolkepli and Kamarulzaman (2015) focusing on the role of media needs and innovative features, where the main objective of the researcher is to investigate how social media and innovation needs influence the application of social media among Internet users. This study uses a mixed method approach, which is qualitative and quantitative. Data collected from in-depth interviews were analyzed through Nvivo 9 while data from survey questionnaires were 
analyzed through Partial Least Parties (PLS). From data analysis, the findings support the use of social media through the benefits of technology or relative advantages are highly supported. An empirical study by Jalali, Kaiser, Siegel, and Madnick ( 2017) found that relative advantages were the number of innovations that were corrected in the past and affecting the continuous use of technology. Shaltoni et al. (2018) examined the key factors that affect the degree of e-marketing adoption among SMEs from an organizational orientation perspective and by employs a cross-sectional survey of just over 135 European SMEs, the finding reveals that the degree of e-marketing adoption is primarily affected by perceived relative advantage. In Malaysia, more and more researchers pay attention to E-commerce studies in the SME sector because they are aware of the importance of SMEs in helping the country generate a wider income today (Sin et al., 2016). According to the researchers, relative advantage appears to be the most significant to influence the adoption or implementation of Ecommerce among the SMEs. Relative advantage is largely defined as a factor that has a positive impact on the adoption of new technologies in previous literature. The higher the technological level, the more likely an organization willing to adopts the technology to replace it with current practice. Therefore, the following proposition is formulated in accordance with this study where relative advantage has been perceived as factors that influence the intention to use affiliate marketing:

Proposition 1: Relative advantage is positively related to the intention to use affiliate marketing.

\section{Compatibility}

As explained by Rogers (2003), compatibility refers to the level at which the innovation is seen consistent with previous ideas, socio-cultural values or perceived innovation is necessary (Rogers, 2003). Compatibility is one of the key determinants of Rogers' innovative theory and is widely used in previous and current research that defines what encourages the adoption of new technologies (AlJabri and Sohail, 2012; Lou et al., 2017). Researchers suggest that for technology to suit others, the technology must be consistent with past experience and meet current needs (Cha, 2013). To Tefertiller (2018), the new experience that users get from the technology should be in line with the expectation of current users and the current lifestyle of the user. At the organizational level, compatibility is an important component that affects management and manager decisions of an organization because if the technology is incompatible with their working value and work culture, they will not adopt the technology. Generally, management and manager decisions are based on their organization and industry needs as these groups are more aware of whether the technology is needed and compatible with their organization to improve performance and sales. Research by ElGohary (2012) also reveals that perceived compatibility is the most important determinant for the use of technology. An innovative study by Ainin et al. (2015) investigated the factors that influence Facebook usage among small and medium enterprises (SMEs) in Malaysia. The researcher reveals that compatibility positively supports the usage of Facebook among the SMEs in Malaysia. Another empirical study by Al-Jabri and Sohail (2012) also found that compatibility is the most significant determinant to predict the adoption of new technology. This finding also supported by other researchers (Faizal Samat, Nor Hakimin Yusoff, Ismail, Annual, and Mamat, 2017; Sandu, Gide, and Karim, 2017; Zolkepli and Kamarulzaman, 2015). Thus, based on the above discussion and findings, this study suggests that: 
INTERNATIONAL JOURNAL OF ACADEMIC RESEARCH IN BUSINESS AND SOCIAL SCIENCES

Vol. 9, No. 2, Feb, 2019, E-ISSN: 2222-6990 C 2019 HRMARS

Proposition 2: Compatibility is positively related to the intention to use affiliate marketing.

\section{Observability}

Observability, the stage where other users or other parties, but not the business owner can see the positive results of using the technology (Rogers, 2003), as well as the innovation, might benefit them (Young, 2017). If the results are easily seen from others, they will likely suggest potential adopters through suggestions and discussions that can facilitate the adoption of such technologies (Chauhan, Mukhopadhyay, and Jaiswal, 2018; Lou et al., 2017). Observability comprises of great quality as a result of consumption and people who see the development as significant in the actual setting of adoption (Moore and Benbasat, 1991). To Chauhan et al. (2018), observability increases interest among residents while relatively less observable innovation will spread out more slowly. Moreover, not all ideas are easy to explain to others, some are easy to communicate with others about the good and bad of new systems or technologies and some are difficult to explain to others. (Kitchen and Panopoulos, 2010). An empirical study done by Teigeler, Lins, and Sunyaev (2018) has utilized the DOI models to explain why cloud service providers might be willing to adopt Continuous Service Certification (CSC). The results of this study showed that observability is the very important driver of CSC adoption. Elmustapha, Hoppe, and Bressers (2018) assessed the adoption of solar heating systems in the Metn neighborhood in Lebanon. The main objective of this study is to analyze which factors best-explained consumers' decision to adopt SWHs. The findings showed that independent observability among the most important determinant to the adoption other than judgment-making and novelty-seeking. For observability, the researchers explained observability found to be significant to the adoption because the management understands the perceived benefits of the e-commerce and they have a strong trust to adopt e-commerce in their prospective business. These findings are consistent with many other authors and scholars (e.g. Chen, 2013; Putzer and Park, 2010; Zolkepli and Kamarulzaman, 2015). Through the above innovative studies, it is believed that observability will influence the intention to use affiliate marketing. Therefore, the following statement is proposed:

Proposition 3: Observability is positively related to the intention to use affiliate marketing.

\section{Theoretical Framework}

There are limited empirical studies and scholars focus on the topic of affiliate marketing. Many factors affecting the adoption of new technologies or systems have been discussed individually in previous studies. These factors include perceived usefulness, perceived ease of use, effort expectancy, performance expectancy, facilitating condition, social influence, and others. Diverse factors are linked to the adoption of technology, either significantly or insignificantly. Three most important factors have been an emphasis in this study, which are the relative advantage, compatibility, and observability. Relative advantage, which explains the advantages underlying technology, is expected to affect the intention to use affiliate marketing. Values, experiences, and needs are an important component of compatibility, which is expected to affect the intention to use affiliate marketing. Besides that, high flexibility, accessibility, and visibility that represent observability are also expected to affect the intention to use affiliate marketing. By viewing at the preferred factors, a theoretical 
INTERNATIONAL JOURNAL OF ACADEMIC RESEARCH IN BUSINESS AND SOCIAL SCIENCES

Vol. 9, No. 2, Feb, 2019, E-ISSN: 2222-6990 C 2019 HRMARS

framework has been created to show the influence of relative advantage, compatibility, and observability on the intention to use affiliate marketing. The theoretical framework is represented in Figure 1.

Independent Variables

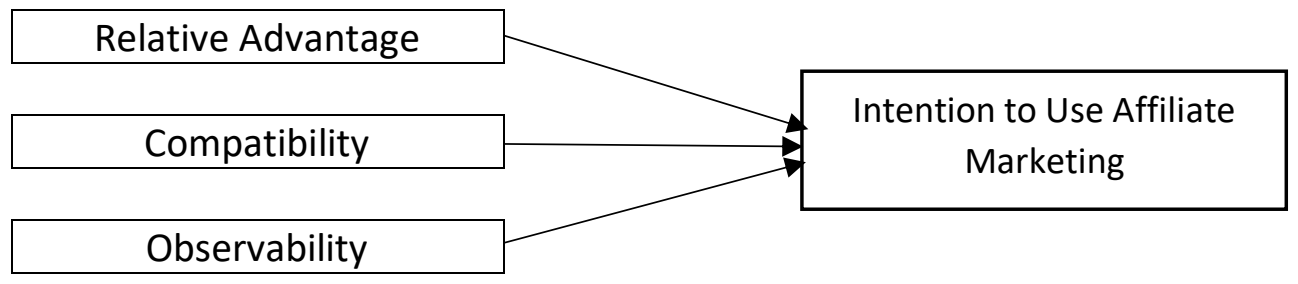

Figure 1: Proposed Theoretical Framework

\section{Research Implications}

With the increased volume of businesses registered in the e-commerce market, competition between organizations and industries has become even more intense. The success of an organization and industry is not only influenced by the products and services offered to customers, but also effective marketing techniques to increase the numbers of customer worldwide. As the internet and technology are getting better, online marketing tools are becoming increasingly important. The use of an online marketing tool in marketing activities often depends on the suitability, current practice, and culture of an organization. Affiliate marketing is explored in this paper as one of the critical factors related to the organization's product visibility, advertising cost, and return on investment (ROI). Organizations can increase productivity, sales, and reduce spending on marketing activities that do not necessarily provide profitable results if they hire third-party (affiliate marketers) as they only need to pay if their product is purchased by the customer through affiliate marketing efforts (pay based on commission). The present study, the researcher aims to show a better understanding of the affiliate marketing concept and the factors that influence the intention to use affiliate marketing such as relative advantage, compatibility, and observability. In terms of practical implications, there is still no substantive guide to demonstrating how this technique should be applied to business and industrial situations. Therefore, management and managers are encouraged to look into the potential of affiliate marketing within their organization. They are recommended to fully support the use of affiliate marketing in their organizations because this technique is believed to be able to increase sales while reducing costs on marketing techniques that are not appropriate for their organization or industry settings. When profitable marketing techniques are used, organizations can increase the number of new customers that will indirectly increase sales. In improving organizational competitiveness, an understanding of the three most top factors such as relative advantage, compatibility, and observability is very important.

\section{Conclusion}

The e-commerce market is expanding and organizations start to assess the advantages and disadvantages of every online marketing tool, as well as which ones are better suited to position their 
brands in the market. Some organizations spend too much on various online marketing tools, this increases their marketing costs while there is no guarantee that using multichannel will increase sales. Some organizations and industries still facing the difficulty to select the best and cost-effective online marketing tools that have the ability to increase sales. Increased number of customers and sales is are the indicators of the effectiveness of online marketing tools used. Affiliate marketing is one important tool of online marketing and is believed to be more cost-effective, increase an organization's product visibility, as well as the ROI. Therefore, a better understanding of affiliate marketing concepts and the factors that influence the intention to use affiliate marketing is essential for all researchers, organizations, and industries. Through a better understanding of factors, it can enhance investigative knowledge about factors affecting the use of affiliate marketing and organizations can be aware of affiliate marketing and its advantages to support and increase the organization's sales while reducing costs on marketing techniques that are not appropriate for the organization or industry settings. In order for an organization to increase sales, affiliate marketing can help to increase the number of new customers that will indirectly increase sales.

\section{Acknowledgments}

I am particularly grateful for the assistance given by my supervisor, Dr. Ong Choon Hee for his continuous guidance and support throughout this study.

\section{References}

Al-Jabri, I. M., \& Sohail, M. S. (2012). Mobile Banking Adoption: Application of Diffusion of Innovation Theory. Journal of Electronic Commerce Research, 13(4), 379-391.

Beranek, L. (2018). An empirical investigation of factors that influence commitment and active participation in in-house affiliate marketing network. International Journal of Electronic Business, 14(3), 189-211.

Brear, D., \& Barnes, S. (2008). Assessing the value of online affiliate marketing in the UK financial services industry. International Journal of Electronic Finance, 2(1), 1-17.

Cha, J. (2013). Predictors of television and online video platform use: A coexistence model of old and new video platforms. Telematics and Informatics, 30(4), 296-310.

Chauhan, S., Mukhopadhyay, S., \& Jaiswal, M. (2018). The adoption of mobile app for B2C transaction in platform marketplace: An empirical examination of key drivers. Journal of Information Technology Case and Application Research, 20(1), 1-14.

Chen, C. (2013). Perceived risk, usage frequency of mobile banking services. Managing Service Quality: An International Journal, 23(5), 410-436.

Duffy, D. L. (2005). Affiliate marketing and its impact on e-commerce. Journal of Consumer Marketing, 22(3), 161-163.

Dwivedi, Y. K., Rana, N. P., \& Alryalat, M. A. A. (2017). Affiliate marketing: An overview and analysis of emerging literature. The Marketing Review, 17(1), 33-50.

El-Gohary, H. (2012). Factors affecting E-Marketing adoption and implementation in tourism firms: An empirical investigation of Egyptian small tourism organisations. Tourism Management, 33(5), 1256-1269. 
INTERNATIONAL JOURNAL OF ACADEMIC RESEARCH IN BUSINESS AND SOCIAL SCIENCES Vol. 9, No. 2, Feb, 2019, E-ISSN: $2222-6990$ ๑ 2019 HRMARS

Elmustapha, H., Hoppe, T., \& Bressers, H. (2018). Consumer renewable energy technology adoption decision-making; comparing models on perceived attributes and attitudinal constructs in the case of solar water heaters in Lebanon. Journal of Cleaner Production, 172, 347-357.

Samat, M., Yusoff, M., Ismail, M., Annual, N., \& Mamat, M. (2017). Technological Factor and Social Media Marketing Adoption Among SMEs in Kelantan: In Proceedings of the 2nd International Conference on Economic Education and Entrepreneurship, Bandung, 2017, Indonesia: SCITEPRESS Science and Technology Publications.

Fox, P., \& Wareham, J. (2010). Governance Mechanisms in Internet-Based Affiliate Marketing Programmes in Spain. International Journal of E-Business Research, 6(1), 1-18.

Jalali, M. S., Kaiser, J. P., Siegel, M., \& Madnick, S. (2017). The Internet of Things (IoT) Promises New Benefits and Risks: A Systematic Analysis of Adoption Dynamics of loT Products. Retrieved June 10, 2018, from SSRN: https://doi.org/10.2139/ssrn.3022111

Janssen, D., \& van Heck, E. (2007). How Will Online Affiliate Marketing Networks Impact Search Engine Rankings? Retrieved from SSRN: https://papers.ssrn.com/abstract=1008391

Jansson, J. (2011). Consumer eco-innovation adoption: assessing attitudinal factors and perceived product characteristics. Business Strategy and the Environment, 20(3), 192-210.

Kaminski, J. (2011). Diffusion of Innovation Theory. Retrieved December 1, 2017, from CJNI: http://cjni.net/journal/?p=1444

Kitchen, P. J., \& Panopoulos, A. (2010). Online public relations: The adoption process and innovation challenge, a Greek example. Public Relations Review, 36(3), 222-229.

Lammenett, E. (2017). Praxiswissen Online-Marketing: Affiliate- und E-Mail-Marketing, Suchmaschinenmarketing, Online-Werbung, Social Media, Facebook. Retrieved January 15, 2018, from Springer Gabler: http://b-ok.cc/book/2920503/b7062a

Lou, L., Tian, Z., \& Koh, J. (2017). Tourist Satisfaction Enhancement Using Mobile QR Code Payment: An Empirical Investigation. Sustainability, 9(7), 1-14.

Mariussen, A., Daniele, R., \& Bowie, D. (2010). Unintended consequences in the evolution of affiliate marketing networks: a complexity approach. The Service Industries Journal, 30(10), 1707-1722.

Mazurek, G., \& Kucia, M. (2011). Potential of Affiliate Marketing. The 7th International Conference Management of Technological Changes - MTC 2011. Retrieved December 30, 2018, from Electronic Resources: https://goo.gl/3qxbxe

Moore, G. C., \& Benbasat, I. (1991). Development of an Instrument to Measure the Perceptions of Adopting an Information Technology Innovation. Information Systems Research, 2(3), 192-222.

Newton, S., \& Ojo, M. (2018). Driving Traffic and Customer Activity Through Affiliate Marketing: Understanding and Addressing the Differences Between Affiliate Marketing in the USA. In S. Singh (Ed.), Driving Traffic and Customer Activity Through Affiliate Marketing (pp. 101-112). Hershey, PA: IGI Global.

Phillips, E. (2015). Retailers scale up online sales distribution networks. Retrieved June 26, 2018, from The Wall Street Journal: http://www.wsj.com/articles/retailers-scale-up-online-salesdistributionnetworks-1447792869

Puklavec, B., Oliveira, T., \& Popovič, A. (2018). Understanding the determinants of business intelligence system adoption stages: An empirical study of SMEs. Industrial Management \& Data Systems, 118(1), 236-261. 
INTERNATIONAL JOURNAL OF ACADEMIC RESEARCH IN BUSINESS AND SOCIAL SCIENCES Vol. 9, No. 2, Feb, 2019, E-ISSN: 2222-6990 C 2019 HRMARS

Putzer, G. J., \& Park, Y. (2010). The effects of innovation factors on smartphone adoption among nurses in community hospitals. Perspectives in health information management, 7(Winter), 1b.

Rogers, E. M. (1983). Diffusion of innovations 3rd Edition. New York, NY : The Free Press ; Macmillan Publishing Co. Inc.

Rogers, E.M. (2003). Diffusion of innovations 5th Edition. New York, NY: The Free Press: Simon \& Schuster, Inc.

Sandu, R., Gide, E., \& Karim, S. (2017). The impact of innovative strategies to influence the adoption of cloud based service success in Indian small and medium enterprises (SMEs). International Journal of Arts \& Sciences, 10(2), 389-400.

Shaltoni, A. M., West, D., Alnawas, I., \& Shatnawi, T. (2018). Electronic marketing orientation in the Small and Medium-sized Enterprises context. European Business Review, 30(3), 272-284.

Sin, K. Y., Osman, A., Salahuddin, S. N., Abdullah, S., Lim, Y. J., \& Sim, C. L. (2016). Relative Advantage and Competitive Pressure towards Implementation of E-commerce: Overview of Small and Medium Enterprises (SMEs). Procedia Economics and Finance, 35, 434-443.

Sun, S., Cegielski, C. G., Jia, L., \& Hall, D. J. (2018). Understanding the Factors Affecting the Organizational Adoption of Big Data. Journal of Computer Information Systems, 58(3), 193-203.

Tefertiller, A. (2018). Media Substitution in Cable Cord-Cutting: The Adoption of Web-Streaming Television. Journal of Broadcasting \& Electronic Media, 62(3), 390-407.

Teigeler, H., Lins, S., \& Sunyaev, A. (2018). Drivers vs. Inhibitors - What Clinches Continuous Service Certification Adoption by Cloud Service Providers? Retrieved November 1, 2018, from ScholarSpace: https://scholarspace.manoa.hawaii.edu/handle/10125/50600

Wong, R. M. M., Wong, S. C., \& Ke, G. N. (2018). Exploring online and offline shopping motivational values in Malaysia. Asia Pacific Journal of Marketing and Logistics, 30(2), 352-379.

Yap, J. B. H., \& Chua, K. L. (2018). Application of e-booking system in enhancing Malaysian property developers' competitive advantage: A blue ocean strategy? Property Management, 36(1), 86-102.

Young, J. A. (2017). Facebook, Twitter, and Blogs: The Adoption and Utilization of Social Media in Nonprofit Human Service Organizations. Human Service Organizations: Management, Leadership \& Governance, 41(1), 44-57.

Zolkepli, I. A., \& Kamarulzaman, Y. (2015). Social media adoption: The role of media needs and innovation characteristics. Computers in Human Behavior, 43, 189-209. 